\title{
Prevalence of Linea Alba Buccalis in Bangladeshi Population
}

\author{
Anisuzzaman $\mathrm{M} \mathrm{M}^{1^{*}}$, Khan $\mathrm{M} \mathrm{TI}^{2}$, Hasan $\mathrm{S}^{3}$, Adnan $\mathrm{N}^{4}$, Afrin $\mathrm{A}^{5}$
}

\section{AFFILIATION:}

1. Dr. Mostafa Md. Anisuzzaman; FCPS, BDS Assistant Registrar, Department of Oral and Maxillofacial surgery Bangladesh Dental College, Dhanmondi, Dhaka.

2. Dr. Mohammad Tariqul Islam Khan; DDS, BDS Assistant Professor, Department of Oral Anatomy and Physiology Bangladesh Dental College, Dhanmondi, Dhaka.

3. Dr. Sajid Hasan, FCPS, BDS

Assistant Professor, Department of Oral \& Maxillofacial Surgery Ibrahim Medical College (Dental Unit), Shahbag, Dhaka

4. Dr. Nubad Adnan; BDS Medical officer, Dental Surgery Department Birdem General Hospital, Shabagh, Dhaka.

5. Dr. Alia Afrin; BDS Dental Surgeon, Private Practitioner

\section{Article info.}

Received: $29^{\text {th }}$ March, 2019

Accepted: $15^{\text {th }}$ August, 2019

Volume: 9, Issue-2 October, 2019

DOI: https://doi.org/10.3329/updcj.v9i2.43734

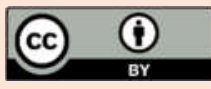

(c) Authors retain copyright and grant the journal right of first publication with the work simultaneously licensed under Creative Commons Attribution License CC - BY 4.0 that allows others to share the work with an acknowledgment of the work's authorship and initial publication in this journal.

https://creativecommons.org/licenses/by/4.0/

Publisher: Update Dental College, Dhaka, Bangladesh

Web: www.updatedentalcollege.edu.bd

E-mail: updcj@hotmail.com

\footnotetext{
* Corresponding Author
}

Dr. Mostafa Md. Anisuzzaman; FCPS, BDS

Assistant Registrar, Department of Oral and Maxillofacial surgery Bangladesh Dental College, Dhanmondi, Dhaka.

E-mail: dmukul808@gmail.com

\section{9) Citation}

Anisuzzaman M M, Khan M T I, Hasan , Adnan N, Afrin A. Prevalence of Linea Alba Buccalis in Bangladeshi Population. Update Dental College Journal. 2019 October; 9(2): 17-19 DOI: https://doi.org/10.3329/updci.v9i2.43734

\begin{abstract}
Aim: The aim of this study is to determine the prevalence of linea alba buccalis in Bangladeshi population.

Objective: To study the prevalence of frictional keratosis encompassed by the particular age groups with and without parafunctional habits.

Background: Linea alba buccalis is a thickened whitish line on the buccal mucosa at the horizontal of the occlusal plane extending from the corners of the mouth to the posterior teeth. It is usually correlated with the frictional activity of the teeth and may be emphasized by cheek biting or parafunction. The appearance is caused by a keratosis of the epithelial tissue, which cannot be rubbed off. It is asymptomatic and is frequently present bilaterally. The condition does not require treatment.

Logic: Linea alba buccalis being common finding, it may also found in individuals who chew tobacco, a thorough analysis of the prevalence along with the various contributing factors would assist in prompt treatment and prevent further complications.
\end{abstract}

KEYWORDS: Linea alba buccalis, white raised patch, normal anatomic variation and awareness.

\section{INTRODUCTION}

Linea Alba is a natural anatomic alteration of the oral cavity. ${ }^{1}$ It is present at the level of occlusal line on the both side of the buccal mucosa. It is benign solidification of the mucosa inside of the mouth due to overflow keratin deposition. It is more regularly seen in adults than in children. ${ }^{2}$ Adults experience linea alba more frequently than children. Moreover, cheek biting is far more prevalent in women than in men. So women are more doubtlessly to grow the condition from biting behaviors.

The linea alba is a horizontal streak on the inner surface of the cheek, level with the biting plane. It usually extends from the commissure to the posterior teeth and can extend to the inner lip mucosa and corners of the mouth. ${ }^{3}$ It is a common finding and most likely combine with pressure, frictional irritation, or sucking trauma from the facial surfaces of the teeth. It may be found in person who chew tobacco, and may be mistaken for a lesion requiring treatment.

In a Turkish study among adolescents (13-16 years of age) linea alba was the second commonest finding which accounts for $5.3 \%$ of the total. ${ }^{4}$ It is believed that parakeratosis occur along the line of the occlusal plane as the cheeks sucks in due to the negative pressure. ${ }^{5}$ Linea alba is asymptomatic and generally considered a normal variation than pathological. ${ }^{6}$ In our study, it was attempted to focus the prevalence of linea alba in Bangladeshi population.

\section{Material and Methods:}

The study was supervised on patients attending the Bangladesh dental college between January 2017 and 
December 2017. Informed consent was collected from patients participating in the study. Personal data including age, gender and social habits were recorded. Data were analyzed using the chi square (Statistics). A $p$ value of $\leqslant 0.05$ was considered statistically significant.

Results:

Figure: 1 Distribution of sex of patient

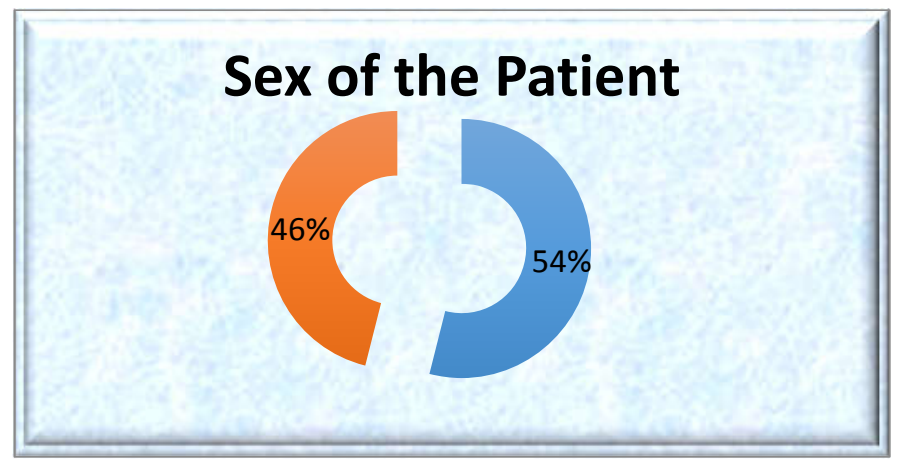

Figure: 1 Showing sex distribution where Male was 46\% and Female 54\%.

Table: 1 Distribution of age of the patient $(n=500)$

\begin{tabular}{ccc}
\hline Age & Frequency & Percentage\% \\
\hline $11-20$ & 27 & $5.5 \%$ \\
$21-30$ & 42 & $8.4 \%$ \\
$31-40$ & 105 & $21 \%$ \\
$41-50$ & 217 & $43.4 \%$ \\
$51-60$ & 71 & $14.2 \%$ \\
$60+$ & 38 & $7.6 \%$ \\
\hline
\end{tabular}

Table 1 Showing most common age group was $41-50,43.4 \%$ and minimum age was 13 years and maximum age was 79 years.

Table: 2 Distribution of Linea Alba $(n=500)$

\begin{tabular}{|c|c|c|c|c|c|c|c|}
\hline \multirow{3}{*}{$\begin{array}{l}\text { Linea } \\
\text { Alba }\end{array}$} & \multicolumn{6}{|c|}{ Gender } & \multirow{3}{*}{$\begin{array}{l}\mathrm{p}- \\
\text { Value }\end{array}$} \\
\hline & \multicolumn{2}{|c|}{ Male } & \multicolumn{2}{|c|}{ Female } & \multicolumn{2}{|c|}{ Total } & \\
\hline & $\mathrm{N}$ & $\%$ & $\mathrm{~N}$ & $\%$ & $\mathrm{~N}$ & $\%$ & \\
\hline Present & 107 & $39.6 \%$ & 129 & $56.1 \%$ & 236 & $47.2 \%$ & \\
\hline Absent & 163 & $60.4 \%$ & 101 & $43.9 \%$ & 264 & $52.8 \%$ & 0.001 \\
\hline Total & 270 & $100 \%$ & 230 & $100 \%$ & 500 & $100 \%$ & \\
\hline
\end{tabular}

Table 2 showing linea alba present in $39.6 \%$ male and absent in $60.4 \%$ male. One the other site it present in $56.1 \%$ female and absent in $43.9 \%$ female.

Table: 3 Distribution of Para functional habits

\begin{tabular}{|c|c|c|c|c|c|c|c|}
\hline \multirow{3}{*}{$\begin{array}{l}\text { Para } \\
\text { functional } \\
\text { habit }\end{array}$} & \multicolumn{6}{|c|}{ Gender } & \multirow{3}{*}{$\begin{array}{l}\mathrm{p}- \\
\text { Value }\end{array}$} \\
\hline & \multicolumn{2}{|c|}{ Male } & \multicolumn{2}{|c|}{ Female } & \multicolumn{2}{|c|}{ Total } & \\
\hline & $\mathrm{N}$ & $\%$ & $\mathrm{~N}$ & $\%$ & $\mathrm{~N}$ & $\%$ & \\
\hline Present & 103 & $38.1 \%$ & 94 & $40.9 \%$ & 197 & $39.4 \%$ & \\
\hline Absent & 167 & $61.9 \%$ & 136 & $59.1 \%$ & 303 & $60.6 \%$ & 0.006 \\
\hline Total & 270 & $100 \%$ & 230 & $100 \%$ & 500 & $100 \%$ & \\
\hline
\end{tabular}

Table 3 showing para functional habits present in $38.1 \%$ male and absent in $61.9 \%$ male. One the other site it present in $40.9 \%$ female and absent in $59.1 \%$ female.
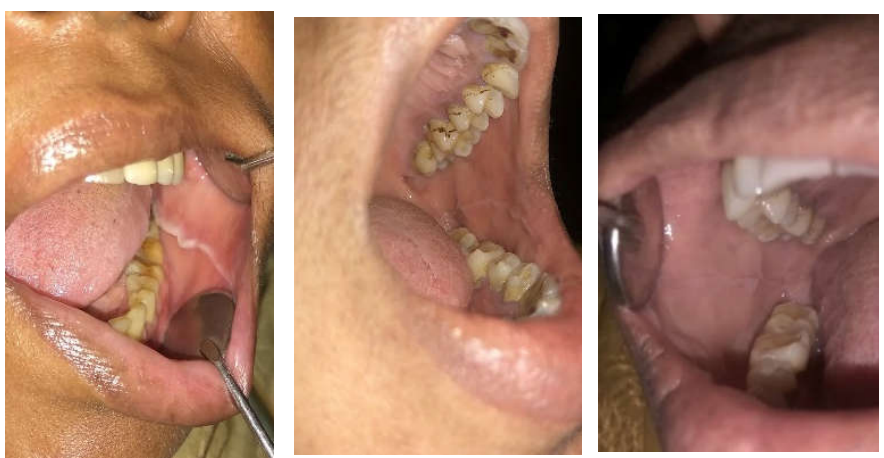

Figure: 2 Photography of Linea Alba Buccalis

\section{DISCUSSION:}

Linea alba, a normal variation of oral mucosa, is described as a slightly raised, usually bilateral, whitish line traversing the corner of the mouth as far posterior as the last molar tooth. ${ }^{7}$ The study, linea alba was the most common finding with a prevalence rate of $7.8 \%$. Parlak et al. reported it to be lesion in Turkish adolescents, with a prevalence of $5.3 \%{ }^{8}$

Linea alba was seen in $4.80 \%$. It was highly significantly more common among females (5.86\%) than in males (3.64\%). This prevalence is comparable to the finding by Cebeci et al. ${ }^{9}$ in Turkey (4.2\%), but it is lower than that found by Martinez and Garcia pola [10.1\%]. ${ }^{3}$

In our study total of 500 patients were included, in which 270 were males and 230 were females. Among the 270 males 107 (39.6\%) were presented with linea alba and $38.1 \%$ of males have parafunctional habits. Among the 230 females linea alba were presented $56.1 \%$ and $40.9 \%$ of the females have parafunctional habits.

Most common age group was adult which was 41-50 years, $43.4 \%$ and minimum age was 13 years and maximum age was 79 years. Linea alba maybe used to evaluate the severity of Para functional Habit.

\section{CONCLUSION}

Prevalence of linea Alba buccalis in the bangladeshi population was important to measure the level of Para functional. It also helps to evaluate the intermission of habits, such as cheek biting and aggressive oral hygiene, adjustment of orthodontic elements, including uneven teeth, dentures and other appliances.

In the present research, the prevalence of linea alba buccalis is more common among the adults particularly females associated mostly with Para functional habit.

This study highlights the need for few community awareness health programs at a larger scale. The patient might even inquire counseling to help manage habits that cause or exacerbate linea Alba. The dentist or oral pathologist seemingly will schedule a follow-up appointment to determine whether or not the condition improved. 


\section{REFERENCES:}

1. Ambika L, Vaishali Kr, Shivayogi H, Sudha P. Prevalence of oral mucosal lesions and variations in Indian public school children. Braz. J oral Sci., 2011; 10(4): 288-293.

2. Denny C, Ahmed J, Ongole R, Shenoy N, Binnal A; Bilaterally occurring mucosal alterations of the oral cavity- a review. International Journal of Medical Research \& Health Sciences, 2015; 4(3): 680-5. https://doi.org/10.5958/2319-5886.2015.00130.7

3. Martínez Al, García-Pola MJ. Epidemiological study of oral mucosal pathology in patients of the Oviedo School of Stomatology. Med Oral 2002; 7(1): 4-16.

4. Parlak AH, Koybasi S, Yavuz T, Yesildal N, Aydogan I, et al. Prevalence of oral lesions in 13 to 16 year old students in Duzce, Turkey. Oral Diseases. 2006; 12: 552-558.https://doi.org/10.1111/j.1601-0825.2006.01235.x

PMid:17054767

5. Seoane LM, Aguado SA, Varela-Centelles PI, Vazquez GJ, Romero MA, et al. Oral Mucosa: variations from normalcy, part I. Cutis. 2002; 69: 131-131.

6. Bhattacharyya I, Chehal HK. White lesions. Otolaryngologic Clinics of North America. 2011; 44: 109-131.

https://doi.org/10.1016/j.otc.2010.09.009 PMid:21093626

7. Seoane Leston JM, Aguado Santos A, Varela-Centelles PI, Vazquez Garcia J, Romero MA, Pias Villamor L. Oral mucosa: Variations from normalcy, partl. Cutis. 2002; 69: 131 - 134.

8. Parlak AH, Koybasi S, Yavuz T, Yesildal N, Anul H, Aydogan I, et al. Prevalence of oral lesions in 13 to 16-year old students in Duzce, Turkey. Oral Dis. 2006; 12: $553-558$.

https://doi.org/10.1111/j.1601-0825.2006.01235.x PMid:17054767

9. Cebeci AR I, Gülşahı A, Kamburoğlu K, Orhan BK, Öztaş B. Prevalence and distribution of oral mucosal lesions in an adult Turkish population. Med Oral Patol Oral Cir Bucal 2009; Jun: 14 (6): E272-7. 